\title{
The status of bedside teaching in the United Kingdom: the student perspective
}

This article was published in the following Dove Press journal:

Advances in Medical Education and Practice

3 June 2015

Number of times this article has been viewed

\author{
Patrick Jones \\ Bhavan Prasad Rai \\ Department of Surgery, Ninewells \\ Hospital, Dundee, UK
}

Purpose: Bedside teaching holds a strong tradition as a key-learning platform for clinical examination in the basic medical clerkship. There is a growing body of literature expressing concern for its witnessed decline in medical school curricula. However, the views of students toward this patient-centered cornerstone in surgical education remain under-reported. The purpose of this study was to gain a nationwide perspective on bedside teaching according to medical students in the United Kingdom.

Materials and methods: An adapted Delphi method was employed to formulate the question series as part of a multi-step process including a pilot study, which was used to construct this survey. The target population was medical undergraduates in the United Kingdom and participants were recruited via social media. Outcomes assessed included exposure to bedside teaching, perceived benefits of clinical simulation, and junior doctors as clinical teachers. Barriers to clinical examination were also evaluated.

Results: Overall, 368 completed surveys were received (completion rate 98.9\%). Final year students were significantly more likely to report receiving insufficient bedside teaching $(P<0.01)$. Seventy-eight percent of the study group agreed that clinical simulation is a good learning tool for clinical examination. Seventy percent of students felt junior doctors were as able as senior doctors to teach. Lack of confidence was identified as the commonest barrier to overcome when examining patients and two-thirds of students felt they burdened patients during bedside teaching.

Conclusion: This prospective study confirms the exposure deficit, which medical students experience in bedside teaching. The junior doctor represents a dynamic clinical teacher in the face of working time directives. Peer learning is a novel solution to such pressures. Work is needed to re-establish the hospital wards as a supportive environment for student learning.

Keywords: teaching skills, learning environment, communication skills

\section{Introduction}

Bedside teaching (BST) involves the ward-based instruction of students by the clinician in the skills of history taking and physical examination. It has been defined as "a part of clinical rounds where both student and instructor attends the patient's bedside to discuss the case and/or demonstrate a clinical procedure". ${ }^{1}$ BST holds a strong tradition as the cardinal, patient-centered, and hands-on teaching modality in the basic medical clerkship. Its role in the undergraduate's learning experience has seen a witnessed decline and it has been estimated to represent just $8 \%$ of the formal clinical teaching delivered by medical schools. ${ }^{2}$ Possible causes for this decline include the rise of imaging technology in the diagnostic process, combined with expeditious laboratory testing. ${ }^{3,4}$ This paradigm shift in medical education has seen a growth in
Correspondence: Patrick Jones Department of Surgery, Ninewells Hospital, Ninewells Avenue, Dundee, DDI 9SY, UK

Tel +44 I382 554010

Fax +44 I382 632327

Email patrick.jonesI@nhs.net
Advances in Medical Education and Practice 2015:6 42I-429 
less traditional learning forums including online e-learning and student-selected projects. A lack of exposure at the undergraduate level has caused concerns over the core competencies demonstrated by junior doctors. ${ }^{5}$ The decline of this Oslerian teaching method, which fosters not only knowledge but also professionalism and communication, has received growing attention in the literature. However, it remains under-reported from the student perspective.

The purpose of this study was to gain a perspective on BST according to medical students in the United Kingdom, using social media, an emerging platform for scientific discussion and debate.

\section{Materials and methods}

A multi-step process was used to construct the survey. The target population was medical undergraduates in the United Kingdom. An adapted Delphi method was employed to develop the question series. For this, an expert panel composed of four senior clinicians was recruited and three cycles of controlled feedback took place before consensus opinion was reached. The draft survey was polled to a crosssection of 40 students. The author panel then reviewed the results of this pilot study in order to scrutinize relevancy, design, and usability. The final nine-item survey (Figure S1) was distributed via Facebook (https://www.facebook. com). This social networking site allows users to join a "group", which serves as a virtual posting board, allowing individuals to connect and share information. Distribution was achieved by advertising the survey on the "group(s)" unofficially affiliated to four United Kingdom accredited medical schools, which were selected at random. Details of the project including intent for research were given such that all authors deemed the criteria for informed consent had been met. In carrying out this study, the Checklist for Reporting Results of Internet E-Surveys (CHERRIES) statement was incorporated, a validated quality improvement tool for internet-based surveys. ${ }^{6}$ Data were collected over a 7-day period using the web-based tool SurveyMonkey ${ }^{\circledR}$ (http://www.surveymonkey.com). All data were handled in a secure, password protected system. Respondent participation was anonymous and voluntary. A prize draw was offered for a surgical atlas textbook.

\section{Exclusion criteria}

- Duplicate entries from the same internet protocol (IP) address.

- Undergraduate students on pre-med course.

- Undergraduates at non-United Kingdom medical school.

\section{Outcomes}

\section{Primary outcomes of interest \\ To assess}

- Amount of supervised BST delivered.

- Clinical simulation as a learning tool.

- Junior doctors as clinical teachers.

- Preferred revision method for clinical examination.

\section{Secondary outcomes of interest}

\section{To evaluate}

- Friendliness of the ward environment.

- Barriers to clinical examination.

- Student perception on burden to patient.

\section{Statistical analysis}

An independent samples $z$-test was used to test statistical significance of the differences where two independent samples (ie, male vs female) were compared. Differences were significant at $95 \%$ confidence interval. Likert scale data analyzed by year of study was tested using the Kruskal-Wallis test. Nominal data analyzed by year of study was tested using the chi-square test. A $P$-value of less than 0.05 was considered significant. PSPP software (version 0.8.4) was used for all calculations.

\section{Results}

In total, 368 completed surveys were received over a 7-day period. One hundred and ninety-nine males and 169 females participated. The completion rate was $98.9 \%$.

\section{Primary outcomes}

\section{Amount of supervised BST delivered}

Perceptions of the amount of BST received were divided. Thirty-five percent either disagreed or strongly disagreed that they had received a good amount of supervised BST, while $45 \%$ agreed or strongly agreed with this statement (Figure 1).

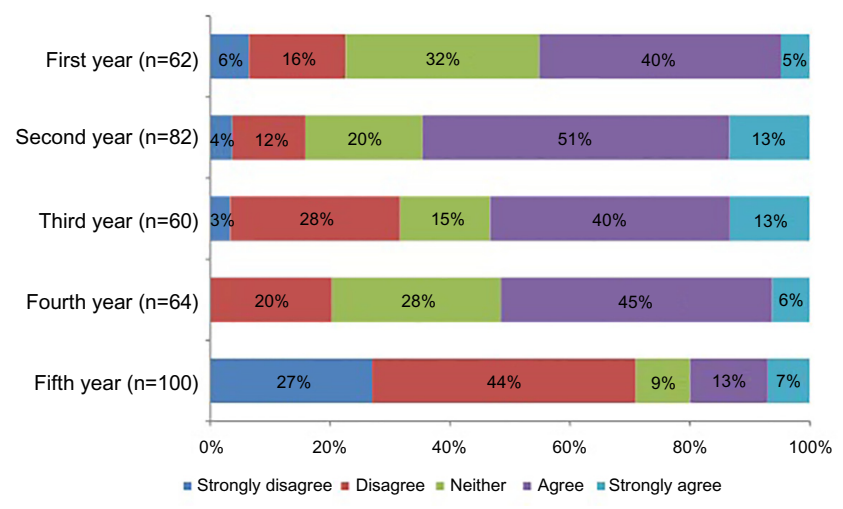

Figure I Question: I have received good amounts of supervised bedside teaching. 
Males were significantly more likely to strongly disagree with this statement (13\%) than females $(6 \%)(P=0.01)$; however, there was not a significant difference at the net disagree level. The number of years studied had a significant effect on the perception of having received a good amount of supervised BST $(\mathrm{H}(4)=65.26, P<0.01)$. Students in their final year of study were the least likely to agree that they had received a good amount of BST (20\%, net agree).

\section{Clinical simulation as a learning tool}

The majority of students surveyed (78\%) either agreed or strongly agreed that clinical simulation with patient actors was a good way of learning bedside clinical skills. Only $4 \%$ disagreed with the value of this approach, and none of the students surveyed strongly disagreed. Female medical students were significantly more likely to favor clinical simulation (84\%, compared to males $73 \%, P<0.01$, Figure 2), while males were more likely to give a neutral response $(22 \%)$ than females $(14 \%, P=0.02)$. The number of years studied had a significant effect on whether clinical simulation with patient actors was considered to be a good way of learning bedside clinical skills $(\mathrm{H}(4)=16.62, P=0.02)$.

\section{Junior doctors as clinical teachers}

There was strong support for junior doctors teaching clinical examination skills, as $70 \%$ of students surveyed agreed that junior doctors were as capable as senior doctors to teach these skills. Significantly more females than males agreed with this statement $(34 \% \mathrm{cf} 22 \%, P<0.01)$; however, there was no statistical difference at the net agree (agree or strongly agree) level. Only 9\% gave a negative response to this statement (disagree or strongly disagree). The number of years studied had a significant effect on whether students agreed that junior doctors were as capable of teaching clinical examination skills as senior doctors $(\mathrm{H}(4)=46.43, P<0.01)$. Looking at the net agree/ disagree scores, it appeared that agreement with this statement increased with years of study while disagreement decreased. By the fifth year, $89 \%$ of students agreed with this statement (Figure 3).

\section{Preferred revision method for clinical examination}

Informal practice with peers $(45 \%)$ and revision sessions with junior doctors (19\%) were the most useful methods of preparation for clinical examination assessments according to the medical students surveyed. These methods were followed, in order, by medical textbooks $(11 \%)$, independent practice on ward patients $(8 \%)$, shadowing clinicians $(7 \%)$, ward rounds $(5 \%)$, and outpatient clinics (4\%). These results were consistent for both males and females, with no significant differences between the two groups. Year of study had a significant impact on which methods students found most useful when preparing for clinical examination $\left(X^{2}(24)=85.86, P<0.01\right)$. Preference for junior doctor revision sessions appeared to increase with year of study, while preference for textbooks, shadowing clinicians, and ward rounds appeared to decline (Table 1).

\section{Secondary outcomes}

\section{Friendliness of the ward environment}

Fifty-seven percent of students surveyed agreed or strongly agreed that they found hospital wards intimidating when they were not accompanied by a clinician. Males were significantly more likely to give a neutral rating to this question

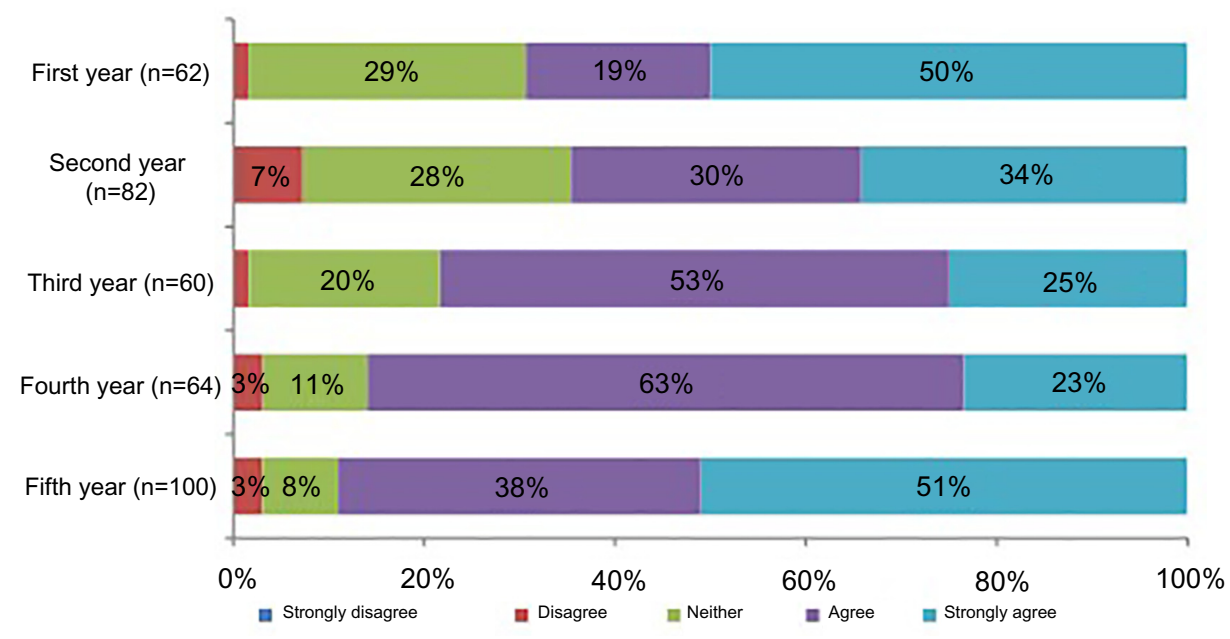

Figure 2 Question: Clinical simulation with patient actors is a good way of learning bedside clinical skills. 


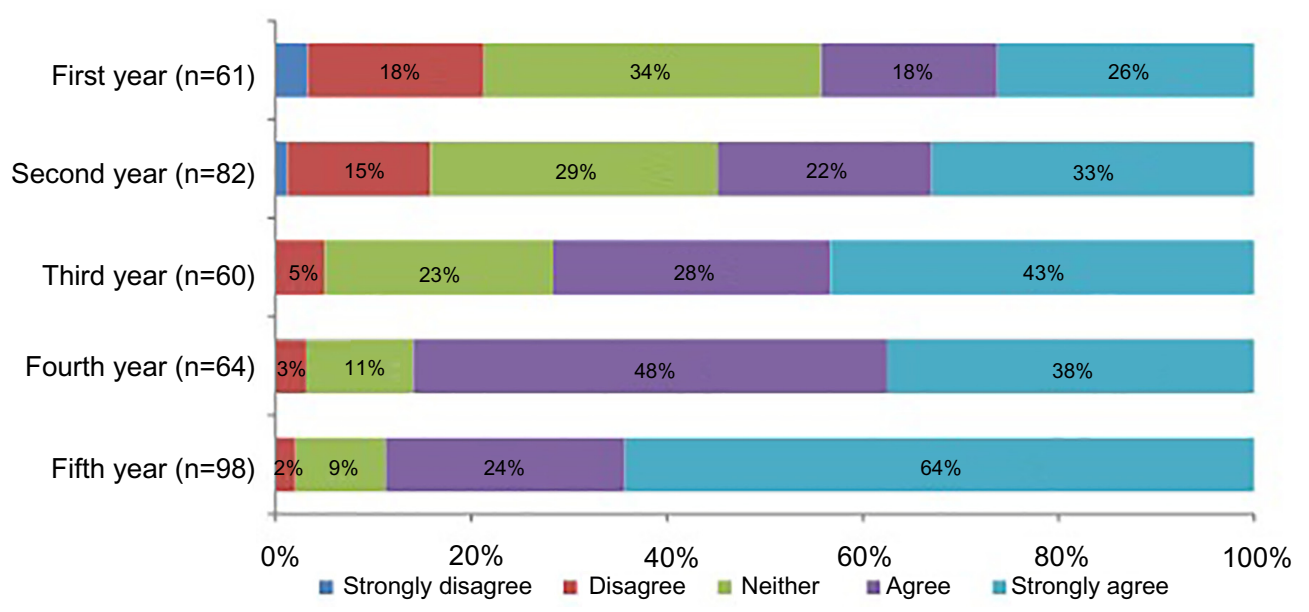

Figure 3 Question: Junior doctors can teach clinical examination skills as well as senior doctors.

than females, $(P=0.03)$. Meanwhile, females were more likely to agree $(P<0.01)$. This difference was also significant at the net agree (agree or strongly agree) level (females $63 \%$, cf males, $P=0.03$ ). Only one in five students surveyed disagreed with this statement $(19 \%, \mathrm{n}=70$ disagree, $1 \%, \mathrm{n}=5$ strongly disagree). The number of years studied had a significant effect on whether hospital wards were found to be intimidating when not accompanied by a clinician $(\mathrm{H}(4)=68.87$, $P<0.01)$. Fourth and fifth year students were most at ease in hospital wards (Table 2).

\section{Barriers to clinical examination}

Lack of confidence was the biggest hurdle for medical students to overcome when examining patients (46\%). This was followed by lack of practice $(21 \%)$, overcoming intimacy boundaries (12\%), fear of causing harm to the patient (11\%), and fear of embarrassment in front of peers (8\%). Only $2 \%$ rated previous bad experience as their biggest hurdle to patient examination (Figure 4). There were no significant differences between males and females.

\section{Student perception on burden to patient}

Sixty-one percent $(n=223)$ of medical students surveyed indicated that they felt they were burdening patients when asking to examine them (agree or strongly agree). Significantly more females than males agreed with this statement $(P<0.01)$, while males were more likely to give a neutral rating $(P<0.01)$. Only $15 \%$ disagreed with this statement (net disagree, Table 3). The number of years studied had a significant effect on whether students felt they were burdening patients by asking to examine them $(\mathrm{H}(4)=56.14$, $P<0.01)$. Fifth year students were the least likely to agree with this statement ( $33 \%$ net agree).

\section{Discussion}

This prospective study on medical student opinion toward BST revealed that undergraduates approaching qualification felt that more of it should be delivered. Clinical simulation was highly valued by students and equally, junior doctors were regarded as effective clinical teachers. The hospital ward was perceived by many students as an

Table I Question: In preparing for an assessment on clinical examination which of the following do you find most useful?

\begin{tabular}{|c|c|c|c|c|c|c|c|c|}
\hline & \multirow{3}{*}{$\begin{array}{l}\text { Total } \\
364\end{array}$} & \multicolumn{2}{|l|}{ Sex } & \multicolumn{5}{|c|}{ Year of study } \\
\hline & & Male & Female & $\begin{array}{l}\text { First } \\
\text { year }\end{array}$ & $\begin{array}{l}\text { Second } \\
\text { year }\end{array}$ & $\begin{array}{l}\text { Third } \\
\text { year }\end{array}$ & $\begin{array}{l}\text { Fouth } \\
\text { year }\end{array}$ & $\begin{array}{l}\text { Fifth } \\
\text { year }\end{array}$ \\
\hline $\mathbf{n}=$ & & 198 & 166 & 61 & 82 & 59 & 63 & 99 \\
\hline Informal practice with peers & $45 \%$ & $41 \%$ & $49 \%$ & $43 \%$ & $40 \%$ & $54 \%$ & $57 \%$ & $37 \%$ \\
\hline Junior doctor revision sessions & $19 \%$ & $22 \%$ & $16 \%$ & $3 \%$ & $9 \%$ & $12 \%$ & $22 \%$ & $38 \%$ \\
\hline Medical textbook(s) on clinical examination & $11 \%$ & $12 \%$ & $10 \%$ & $18 \%$ & $18 \%$ & $10 \%$ & $10 \%$ & $3 \%$ \\
\hline Independent practice on ward patients & $8 \%$ & $8 \%$ & $7 \%$ & $10 \%$ & $6 \%$ & $12 \%$ & $2 \%$ & $9 \%$ \\
\hline Shadowing clinicians & $7 \%$ & $7 \%$ & $8 \%$ & $15 \%$ & $10 \%$ & $8 \%$ & $2 \%$ & $4 \%$ \\
\hline Ward rounds & $5 \%$ & $5 \%$ & $6 \%$ & $11 \%$ & $10 \%$ & $3 \%$ & $2 \%$ & $2 \%$ \\
\hline Outpatient clinics(s) & $4 \%$ & $5 \%$ & $4 \%$ & $0 \%$ & $7 \%$ & $0 \%$ & $6 \%$ & $6 \%$ \\
\hline
\end{tabular}


Table 2 Question: I feel the hospital wards can be an intimidating environment when unaccompanied by a clinician

\begin{tabular}{|c|c|c|c|c|c|c|c|c|}
\hline & \multirow[t]{2}{*}{ Total } & \multicolumn{2}{|l|}{ Sex } & \multicolumn{5}{|c|}{ Year of study } \\
\hline & & Male & Female & $\begin{array}{l}\text { First } \\
\text { year }\end{array}$ & $\begin{array}{l}\text { Second } \\
\text { year }\end{array}$ & $\begin{array}{l}\text { Third } \\
\text { year }\end{array}$ & $\begin{array}{l}\text { Fourth } \\
\text { year }\end{array}$ & $\begin{array}{l}\text { Fifth } \\
\text { year }\end{array}$ \\
\hline $\mathbf{n}=$ & 367 & 199 & 168 & 62 & 82 & 60 & 64 & 99 \\
\hline Strongly disagree & $1 \%$ & $2 \%$ & $1 \%$ & $2 \%$ & $0 \%$ & $3 \%$ & $2 \%$ & $1 \%$ \\
\hline Disagree & $19 \%$ & $20 \%$ & $17 \%$ & $8 \%$ & $12 \%$ & $10 \%$ & $28 \%$ & $31 \%$ \\
\hline Neither disagree nor agree & $22 \%$ & $26 \%$ & $18 \%$ & $19 \%$ & $9 \%$ & $12 \%$ & $20 \%$ & $42 \%$ \\
\hline Agree & $35 \%$ & $30 \%$ & $42 \%^{\wedge}$ & $40 \%$ & $35 \%$ & $53 \%$ & $39 \%$ & $19 \%$ \\
\hline Strongly agree & $22 \%$ & $22 \%$ & $21 \%$ & $31 \%$ & $44 \%$ & $22 \%$ & $11 \%$ & $6 \%$ \\
\hline Disagree total & $20 \%$ & $22 \%$ & $19 \%$ & $10 \%$ & $12 \%$ & $13 \%$ & $30 \%$ & $32 \%$ \\
\hline Agree total & $57 \%$ & $53 \%$ & $63 \%^{\wedge}$ & $71 \%$ & $79 \%$ & $75 \%$ & $50 \%$ & $25 \%$ \\
\hline
\end{tabular}

intimidating environment. A large proportion of students identified a lack of confidence as their greatest hurdle in clinical examination and at the same time considered themselves a burden to patients.

\section{Time pressure}

European Working Time Directives have delivered added constraints for the clinician by magnifying the already time-pressured duties of the doctor in training. Jamshidi and Ozgediz reported this to be the greatest challenge to residentled teaching in their survey at the University of California. Accordingly, they created a "toolbox for time constrained educators", a novel approach to address this issue drawn from experiences at their institution. ${ }^{7}$ It promotes thinking aloud to demonstrate diagnostic reasoning to the student and encourages the clinician to identify impromptu teaching moments. The latter is paramount, as medical student teaching in hospitals moves toward being a 360-degree experience rather than a timetabled one.

\section{Peer-led teaching}

BST programs implemented by newly qualified doctors and senior medical students represent organic solutions to the above-mentioned pressures. Haist et al, using an objective measuring scale, found no significant difference in assessment scores for physical examination after randomly assigning first year students to tutorials either given by fourth year students or faculty members. ${ }^{8}$ Such peer-led teaching has been hypothesized to hold both cognitive and social advantages. "Cognitive congruence" refers to the similar

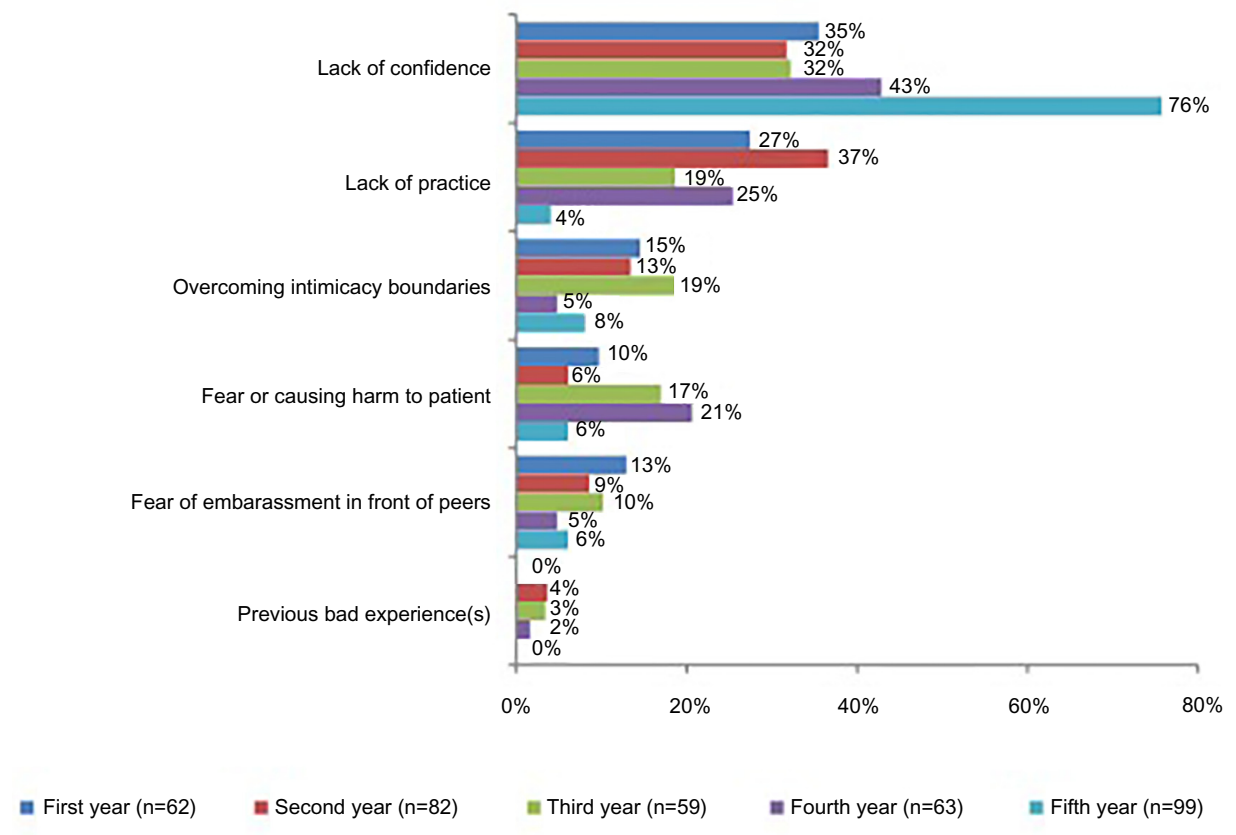

Figure 4 Question: Which of the following options is your biggest hurdle when examining a patient? 
Table 3 Question: I feel like am burdening patients when I ask if I can examine them

\begin{tabular}{|c|c|c|c|c|c|c|c|c|}
\hline & \multirow[t]{2}{*}{ Total } & \multicolumn{2}{|l|}{ Sex } & \multicolumn{5}{|c|}{ Year of study } \\
\hline & & Male & Female & $\begin{array}{l}\text { First } \\
\text { year }\end{array}$ & $\begin{array}{l}\text { Second } \\
\text { year }\end{array}$ & $\begin{array}{l}\text { Third } \\
\text { year }\end{array}$ & $\begin{array}{l}\text { Fourth } \\
\text { year }\end{array}$ & $\begin{array}{l}\text { Fifth } \\
\text { year }\end{array}$ \\
\hline$n=$ & 366 & 196 & 167 & 62 & 81 & 60 & 64 & 99 \\
\hline Strongly disagree & $1 \%$ & $1 \%$ & $1 \%$ & $2 \%$ & $1 \%$ & $0 \%$ & $0 \%$ & $1 \%$ \\
\hline Disagree & $14 \%$ & $16 \%$ & $12 \%$ & $10 \%$ & $5 \%$ & $8 \%$ & $9 \%$ & $31 \%$ \\
\hline Neither disagree nor agree & $24 \%$ & $30 \%^{\wedge}$ & $17 \%$ & $29 \%$ & $11 \%$ & $15 \%$ & $28 \%$ & $34 \%$ \\
\hline Agree & $31 \%$ & $26 \%$ & $39 \%$ & $27 \%$ & $32 \%$ & $43 \%$ & $42 \%$ & $19 \%$ \\
\hline Strongly agree & $30 \%$ & $28 \%$ & $31 \%$ & $32 \%$ & $51 \%$ & $33 \%$ & $20 \%$ & $14 \%$ \\
\hline Disagree total & $15 \%$ & $16 \%$ & $13 \%$ & $11 \%$ & $6 \%$ & $8 \%$ & $9 \%$ & $32 \%$ \\
\hline
\end{tabular}

basic knowledge shared in this setting. As a result, tuition is unconsciously delivered at a more appropriate, academic level. ${ }^{9}$ Senior clinicians have been criticized for overestimating what the student deems as basic knowledge. Furthermore, the parallel social statuses of both parties in the peer learning setting eliminate the formal atmosphere, which can impede self-expression and student confidence. Our findings point to students valuing learning forums where such hierarchical barriers have been removed. This is a possible reason why our study group regarded the teaching abilities of junior doctors so highly.

\section{Clinical simulation}

Clinical simulation using standardized patient actors has emerged as a validated means of instruction and assessment in the domain of medical education. ${ }^{10}$ It grants the opportunity for direct feedback from the actor and allows tailored scenarios to be repeated as necessary. This method of learning was rated highly by students in our study.

\section{Pastoral support}

The need for pastoral support appears to be an important and possibly overlooked component to medical student learning. Medical educators must therefore endeavor to nurture the holistic needs of doctors in training. This is highlighted in our study given the high proportion of students who perceived the ward environment to be intimidating when not accompanied by a clinician. Fifty-one percent of the medical students in a study by De et al reported feeling like an inconvenience when on the wards. Conversely, $95 \%$ of the residents in the study group stated that they would want a medical student on their team. ${ }^{11}$ It would seem that as clinicians, we fail to communicate this viewpoint adequately and it is possible that student learning curves in clinical examination are protracted as a result. Historically in the United Kingdom, medical students were attached to a "firm", a sub unit of specialty specific clinicians and allied health professionals with a designated "home" ward for their patients. By reviving this tradition and involving the student in an established team, an enriched formula for learning would be achieved.

\section{Limitations}

The sample size in this study ( $\mathrm{n}=368)$ was small. The question series was limited to only nine items; however, a high completion rate of $98.9 \%$ was achieved. A novel method of participant recruitment was selected as it befits the reciprocal nature of the modern clinician's social and work life. It therefore represents a revitalization of traditional paper surveys. As outlined by the CHERRIES statement, there exists no established methodology for calculating a single response rate in online surveys and therefore no formal value has been provided in this study. Accordingly, this checklist suggests including a participation rate. This is calculated by using the number of unique visitors to the first page of the advertised survey divided by the number who filled in the first page of the survey. In our study, the participation rate was $83 \%$ (368/441). Recruitment from more medical schools would have added to the generalizability and therefore external validity of our findings.

\section{Conclusion}

This study has highlighted the need for more supervised BST in United Kingdom medical schools. This exposure deficit is likely to serve as a negative determinant for their preparedness for practice and ultimately patient outcomes. The junior doctor represents a dynamic teaching source in the face of the existing time constraints and peer learning is a pragmatic solution to such pressures. Work is needed to re-establish the hospital environment as a supportive platform for student learning.

\section{Disclosure}

The authors report no conflicts of interest in this work and no disclosures of financial interest to declare. 


\section{References}

1. Wojtczak A. Glossary of medical education terms: 9art 1. Med Teach. 2002;24(2):216-219.

2. Sandler G. The importance of the history in the medical clinic and the cost of unnecessary tests. Am Heart J. 1980;100(6 Pt 1):928-931.

3. LaCombe MA. On bedside teaching. Ann Intern Med. 1997;126(3): 217-220.

4. Qureshi Z. Back to the bedside: role of bedside teaching in the modern era. Perspect Med Educ. 2014;3(2):69-72.

5. Forsythe RO, Eylert MF. Medical students and foundation doctors need more exposure to basic urology. Bulletin of The Royal College of Surgeons of England. 2014;96(7):240-243.

6. Eysenbach G. Improving the Quality of Web Surveys: The Checklist for Reporting Results of Internet E-Surveys (CHERRIES). J Med Internet Res. 2004;6(3):e34.
7. Jamshidi R, Ozgediz, D. Medical student teaching: a peer to peer toolbox for time constrained resident educators. J Surg Educ. 2008;65(2): 95-98.

8. Haist SA, Wilson JF, Fosson SE, Brigham NL. Are fourth-year medical students effective teachers of the physical examination. J Gen Intern Med. 1997;12(3):177-181.

9. Lockspeiser TM, O'Sullivan P, Teherani A, Muller J. Understanding the experience of being taught by peers; the value of social and cognitive congruence. Adv Health Sci Educ Theory Pract. 2008;13(3): 361-372.

10. Epstein RM. Assessment in medical education. $N$ Engl J Med. 2007;356(4):387-396.

11. De SK, Henke PK, Ailawadi G, Dimick JB, Colletti LM. Attending, house officer, and medical student perceptions about teaching in the third year medical school general surgery clerkship. J Am Coll Surg. 2004;199(6):932-942. 


\section{Supplementary material}

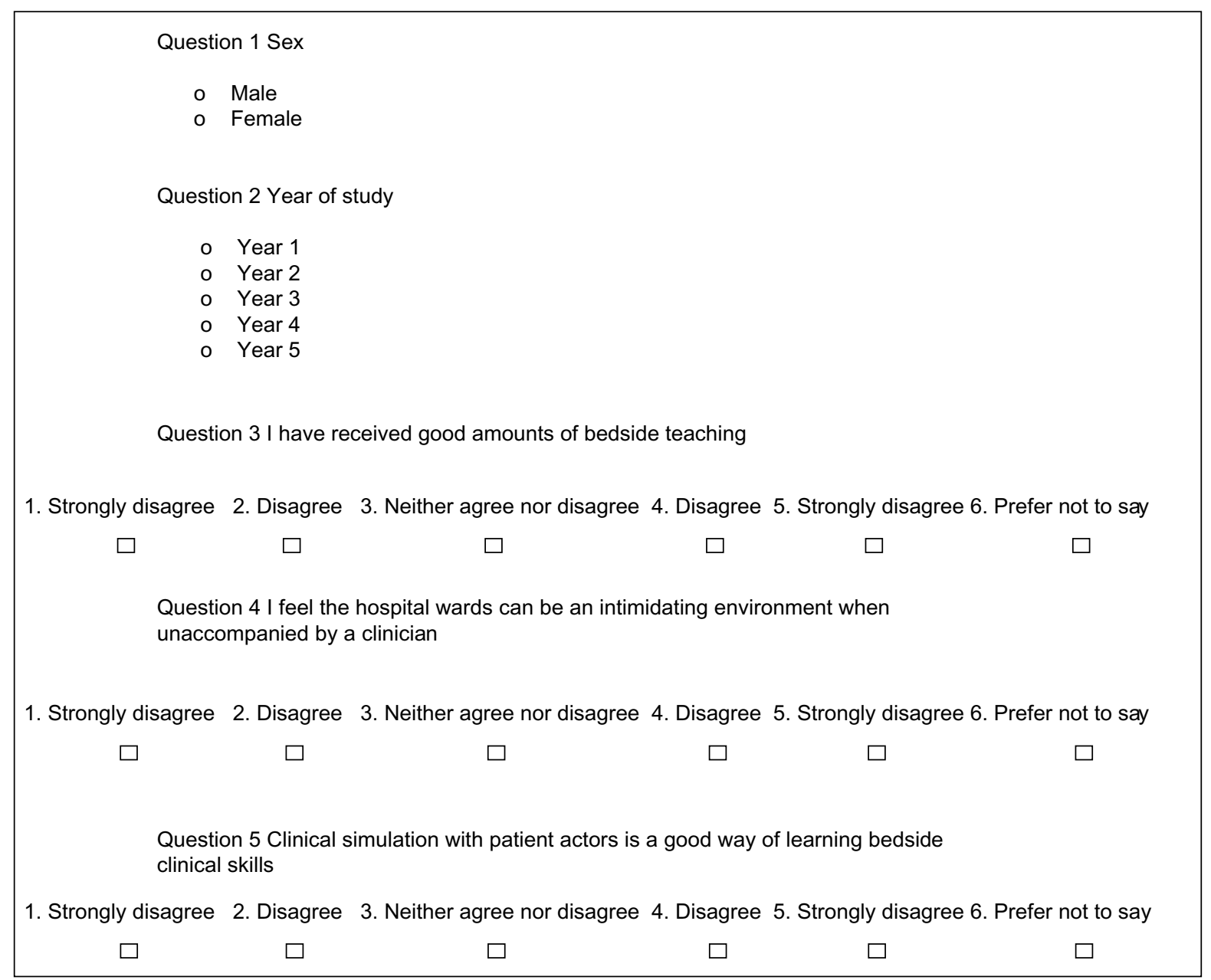

Figure SI (Continued) 
Question 6 I feel like I am burdening patients when I ask if I can examine them

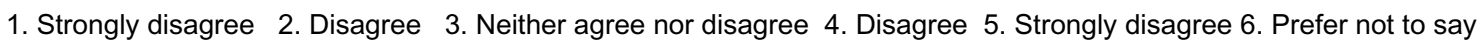

Question 7 Which of the following options is your biggest hurdle when examining a patient?

Please select 1 from the following options:

o Overcoming intimacy boundaries

o Lack of confidence

- Previous bad experience(s)

- Fear of embarrassment in front of peers

- Fear or causing harm to patients

- Lack of practice

Question 8 In preparing for an assessment on clinical examination which of the following do you find most useful?

Please select 1 from the following options:

o Medical textbook(s) on clinical examination

- Ward rounds

o Outpatient clinic(s)

- Junior doctor revision sessions

o Shadowing clinicians

- Informal practice with peers

o Independent practice on ward patients

Question 9 Junior doctors can teach clinical examination skills as well as senior doctors

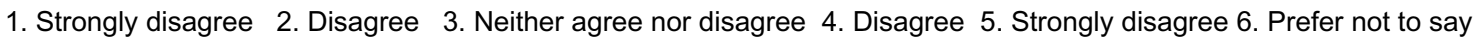<smiles>[SiH3]</smiles>

Figure SI Survey questions.

\section{Publish your work in this journal}

Advances in Medical Education and Practice is an international, peerreviewed, open access journal that aims to present and publish research on Medical Education covering medical, dental, nursing and allied health care professional education. The journal covers undergraduate education, postgraduate training and continuing medical education including emerging trends and innovative models linking education, research, and health care services. The manuscript management system is completely online and includes a very quick and fair peer-review system. Visit http://www.dovepress.com/testimonials.php to read real quotes from published authors.

Submit your manuscript here: http://www.dovepress.com/advances-in-medical-education-and-practice-journal 